\title{
In vitro tests to detect chemical carcinogens
}

\section{By R. Colin Garner, Cancer Research Unit, University of York, York YO ${ }_{5} D D$}

The wide variation in cancer incidence in different parts of the world and in different parts of a country is strongly suggestive of the environment playing a considerable part in cancer causation. This is borne out by studies carried out on migrants who lose the cancer spectrum of their mother country and adopt that of their new home (Doll, 1977; Wynder, 1977). This process can take up to two generations and could well be linked with changes in dietary habits. As cancer has such a strong environmental association it should be possible by altering a person's environment to affect cancer incidence. The problem for research workers at the present time is in identifying these environmental factors. The more one looks into our environment for the presence of carcinogenic chemicals, and the more sensitive our analytical methods, the more carcinogens one finds. Indeed, one begins to wonder why it is that we do not all die of cancer from exposure to carcinogenic chemicals! Examination of tissues from elderly people who have not died of cancer often reveals the presence of premalignant cells which have not developed into frank tumours for reasons we do not understand.

An association of cancer with the environment is not necessarily the same as an association with carcinogenic chemicals. It is unclear at the present time whether environmental influences are actual exposures to harmful chemicals or whether the environment has a modifying effect on such exposure. By the environment we mean all situations in which we find ourselves at work and play. Environment includes the air we breathe, the food we consume, the liquids we drink, the atmosphere we are exposed to, our social habits, etc. To be able to dissect out causes of cancer from this multitude is clearly very difficult; yet this is the task we are faced with if we wish to prevent cancer by altering our environment. The process of alteration is as much an educational as a scientific one, viz cigarette smoking and lung cancer.

Despite the multitude of chemicals we are exposed to, some $20-30$ have been identified as causing cancer in man. These are shown in Table $I$. In animal studies some 1500-2000 chemicals have been identified as being carcinogenic in one species or another. This difference between the number of known human carcinogens and those in animals highlights the problem of identifying human carcinogens. One should not assume from this discrepancy that man is abnormally resistant; indeed, our genetic diversity and nutritional status makes it certain that there will be wide variation in human susceptibility to carcinogens.

\section{Mechanisms of chemical carcinogenesis}

Before one can discuss the types of in vitro tests available to screen for carcinogens it is necessary to discuss how chemical carcinogens might cause $0029-605 \mathrm{~s} / 8 \mathrm{t} / 4013-460480 \mathrm{t} .00 \mathrm{lC}) 198 \mathrm{r}$ The Nutritson Society 


\section{Table I. Known human carcinogens}

(This list is not exhaustive)

$\begin{array}{ll}\text { Thorium } & \text { Mustard gas } \\ \text { Thorotrast } & \text { Nickel ore } \\ \text { Polycyclic aromatic hydrocarbons } & \text { Chrome ore } \\ \text { Melphalan } & \text { Cadmium } \\ \text { Cyclophosphamide } & \text { Agents in isopropyl oil } \\ \text { Oestrogens } & \text { Agents in hardwood furniture manufacture } \\ \text { Silboestrol } & \text { Agents in leather goods manufacture } \\ \text { Steroid contraceptives } & \text { Asbestos } \\ \text { Androgens } & \text { Vinyl chloride } \\ \text { Arsenic } & \text { Aflatoxin } \\ \text { Chlomaphazine } & \text { Smoking } \\ \text { Immunosuppressants } & \\ \text { Phenacetin } & \\ \text { 2-Naphthylamine } & \\ \text { I-Naphthylamine } & \\ \text { Benzidine } & \\ \text { Benzene } & \end{array}$

cancer. Cancer is thought to be a multi-step process starting from tumour initiation and leading finally to a malignant cell. Nearly all the processes involved in the above are unknown except possibly the first. Carcinogenic chemicals are structurally diverse but appear to have as a common feature the property of reacting with cellular macromolecules. Often the chemical has to be metabolized before it is reactive. This hypothesis of electrophilic reactivity, first proposed by the Millers in the late 1960s (Miller, 1970), has stood the test of time. Cellular macromolecules attacked by electrophiles include DNA, RNA and certain basic amino acids within proteins, as well as sulphur nucleophiles such as glutathione, methionine, etc. Which of these reactions is critical to carcinogenesis is a matter of intense debate, with the majority view being that DNA interactions are important, if not essential. The genetic disease, xeroderma pigmenostum, in which patients are abnormally sensitive to sunlight-induced skin cancer lends further support to the importance of DNA, since it is the failure to repair ultra-violet light damage to DNA that gives rise to the large number of skin cancers these patients show (Robbins, 1978).

Tumour initiation is only the first step in the carcinogenic process. Animal studies show that other steps such as promotion may also be important. The tests to be described only screen for tumour initiators and not tumour promoters.

\section{In vitro tests}

The property of reactivity with DNA should allow one to distinguish between carcinogens and non-carcinogens. Most of the current tests available rely on the biological monitoring of DNA reaction as their basis. The tests can be divided into the components set out in Fig. I. 
(a)

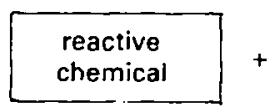

$$
\underset{37^{\circ}}{\stackrel{\text { Incubate }}{\longrightarrow}}
$$

\begin{tabular}{l} 
indicator \\
organism \\
\hline
\end{tabular}

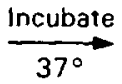

score for DNA reaction

Fig. I. Schematic representations of two in vitro carcinogen tests. (a) Chemical, (b) activation system.

(a) Chemical. In carcinogen screening, chemicals can be tested as solids, liquids or gases. Complex mixtures can be tested as well as human body fluids. The type of chemical to be tested will influence how the test is to be performed, whether a metabolizing enzyme system is required (see later) and what indicator organism will be used. The chemical to be tested will also influence the positive control compound to be used in the test. It is better to test a carcinogen class control compound with related structure to the test chemical rather than an unrelated substance.

Amounts of material available will influence the test, particularly in regard to test sensitivity. For complex mixtures it may often be necessary to undergo some extraction or concentration procedures, particularly if there are toxic materials present which might mask the presence of carcinogens. For the testing of human body fluids, particularly urine, it is necessary to extract out any mutagens prior to testing. Stability of the test chemicals is important in any screening protocol especially for reactive light-sensitive chemicals and this will determine the method of testing.

(b) Activation system. Most carcinogenic chemicals are unreactive towards macromolecules and yet covalent reaction of the chemical occurs in vivo. This is because reactive species are sometimes formed in the body during the process of 'detoxification'. Foreign compounds, not required for intermediary metabolism, are useless for the body's normal functions and are excreted via the urine and faeces. For this to occur, oxidative metabolism, sometimes with conjugation, is necessary to convert lipid soluble compounds to water soluble ones. Without oxidation, foreign compounds would accumulate in the body's fat depots. Furthermore, breakdown products such as bile pigments and steroids are also catabolized by oxidative enzymes. Oxidation within the body is a random process in that no distinction is made between detoxification and activation. This is not to say that there is no specificity to the process for there is considerable. The enzymes catalysing these oxidative processes, known as the mono-oxygenases, are localized in the endoplasmic reticulum of many cell types. The liver is the major site of detoxification in the body but tissues such as the lung and the intestine have activity. Some of the steps in the metabolism of 2-acetylaminofluorene, a wellknown animal carcinogen, are shown in Fig. 2. It can be seen that patterns of metabolism may be extremely complex for particular compounds. Whether a 
chemical is a carcinogen or not will be determined by the balance between how much is activated and how much is detoxified. It is this complex interrelationship that one must attempt to mimic in vitro. I think it is fair to say that we are only at the beginning of this area of research if we are to attempt risk assessment using in vitro tests.

As many, or most, of the biological indicator organisms used for screening have no or limited capacity to oxidatively metabolize foreign compounds, it is necessary to supplement assay systems with mono-oxygenases. Usually a rat liver postmitochondrial supernatant fraction $\left(\mathrm{S}_{9}\right)$ is used for this purpose but preparations from other organs or species have been used, particularly for research purposes. In order to increase the sensitivity of the assay system, the level of mono-oxygenase enzymes is increased by prior treatment of the animals with an inducing agent. The liver mono-oxygenase enzyme system is complex with a number of different cytochrome $\mathrm{P}-45$ os (the terminal cytochrome of the microsomal electron transport chain) (Thomas et al. 1976). Different inducing agents induce different forms of cytochrome $\mathrm{P}_{-45} \mathrm{O}$, thus altering the over-all patterns of metabolism of foreign compounds (Wiebel, 1980). Which inducing agent is best for routine screening is a matter of some controversy. We have carried out an intensive investigation of this problem and some typical results are shown in Fig. 3 (Booth et al. 1980). Depending on the substrate under investigation, different numbers of bacterial mutants are induced when the chemical, tester organism and liver preparation are incubated together. We find that phenobarbitone-induced liver is the most

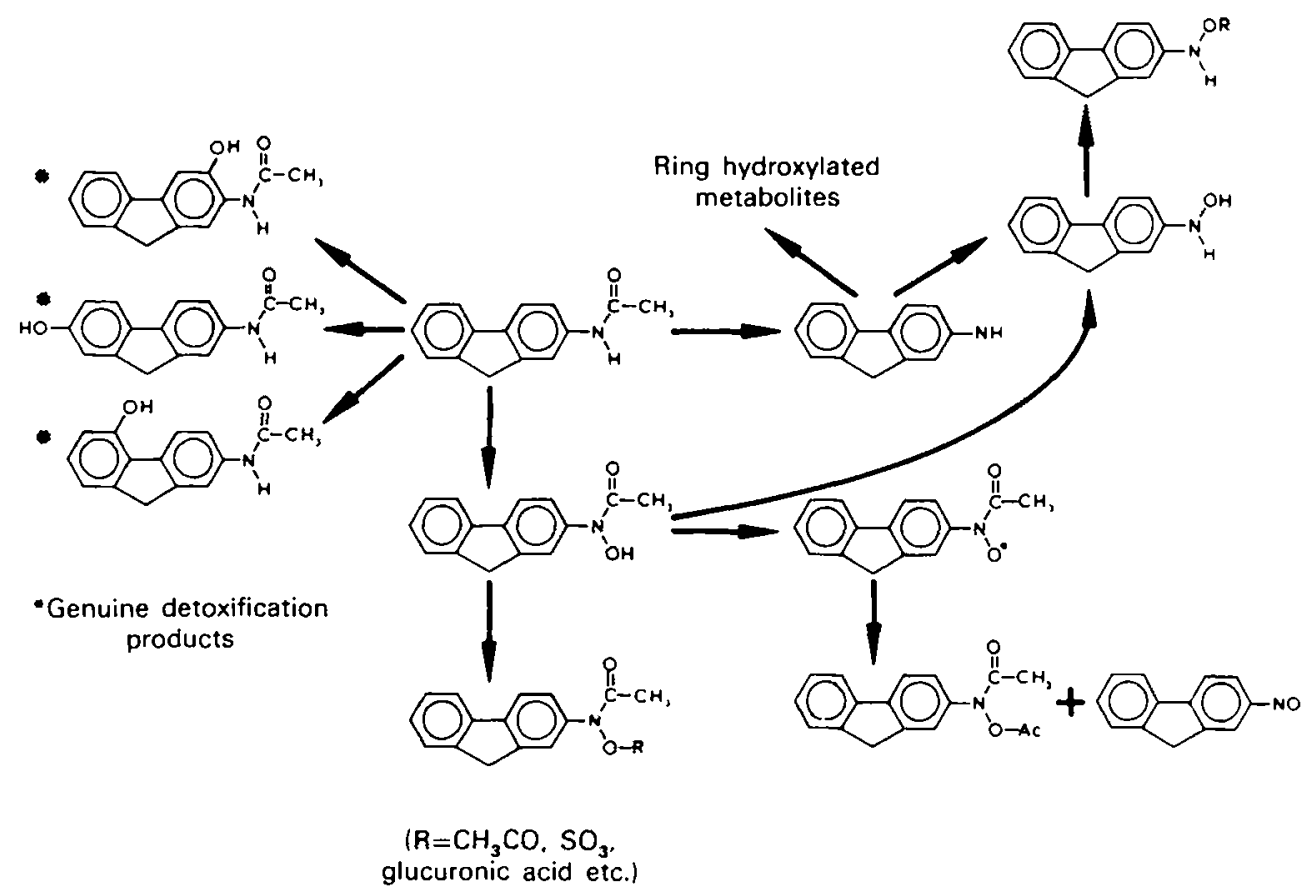

Fig. 2. Some steps in the metabolism of 2-acetylaminofluorene. 
satisfactory for routine screening except for the testing of polycyclic aromatic hydrocarbons, when 3-methylcholanthrene or Aroclor-I254 is superior. The latter inducing agent increases both $\mathrm{P}-45^{\circ}$ and $\mathrm{P}-448$ cytochromes and yet in our hands does not increase mutagenicity of compounds metabolized by the two cytochromes in an additive manner. Little research has been carried out on the effects of storage, method of preparation, etc. on the liver S9 preparation. Furthermore, although the rat is the most widely used species for short-term testing there is no reason why other species such as the hamster should not be examined.

Activation of some chemicals proceeds through a two or more step mechanism, one step being catalysed by the mono-oxygenases and one step by cell soluble enzymes. If assays are only supplemented with mono-oxygenases then reaction with DNA of the tester organism may not occur. To circumvent this problem a number of assays have been devised using mammalian cells. Most of these are
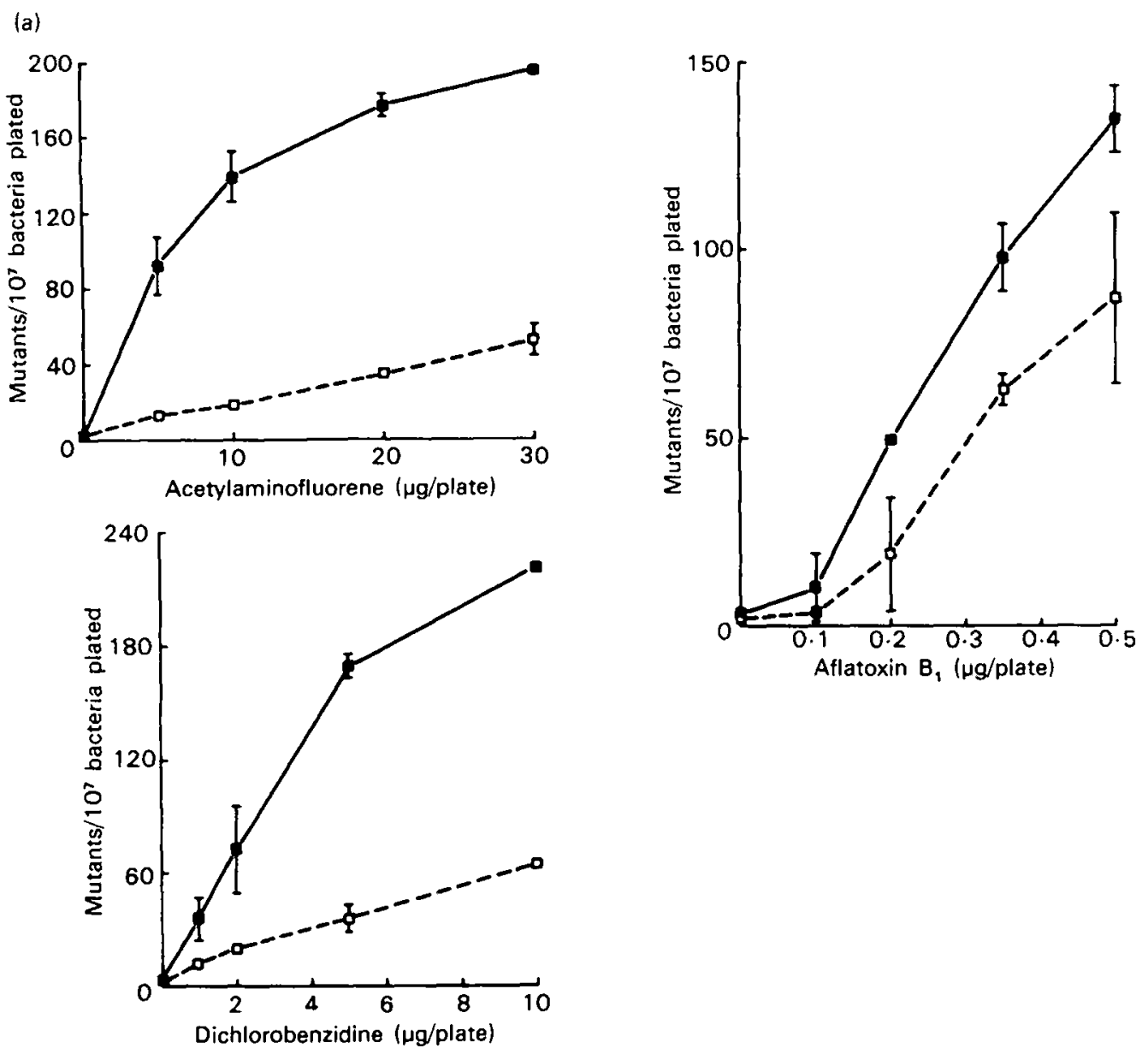

Fig. 3(a). Mutations induced using Aroclor-1 254 ( $\square---\square)$ or phenobarbitone ( rat liver in Salmonella typhimurium TA98. For experimental details see Booth et al. (1980). 

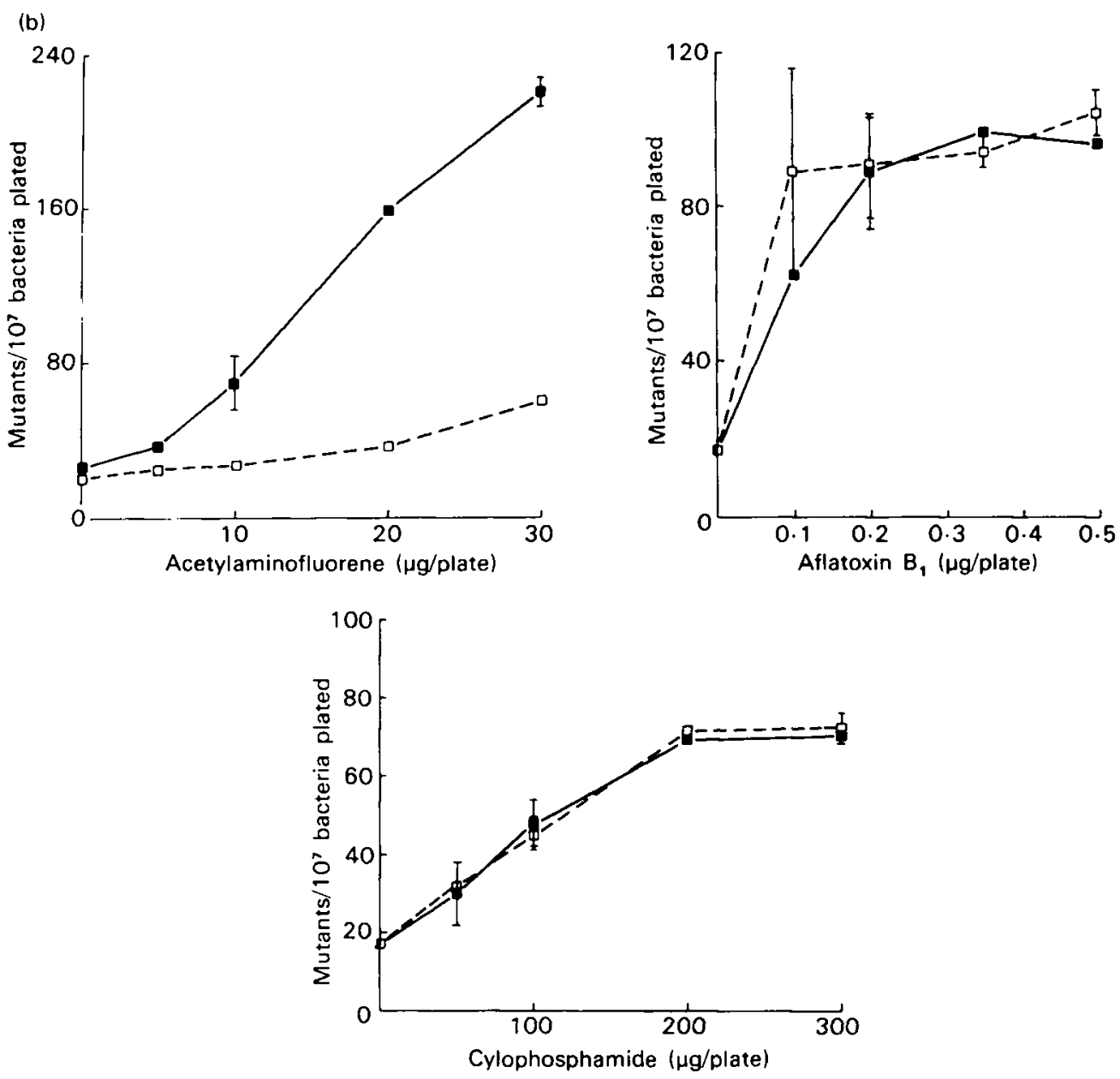

Fig. 3(b). Mutations induced using Aroclor-1254 (口--- $\square$ ) or phenobarbitone ( $\square \square$ ) induced rat liver in Salmonella typhimurium TAroo. For experimental details see Booth et al. (1980).

deficient in mono-oxygenase activity but have the necessary conjugating enzymes. Addition of $S_{9}$ therefore to these assays makes for a powerful assay system, readily able to detect a wide range of genotoxic chemicals. The only exception with regard to S9 addition is where primary hepatocytes are used. These cells mirror the activity of the liver in that they are able to carry out both oxidation and conjugation steps. Unfortunately, they must be prepared freshly for each assay (Williams, 1977). Long-term culturing of these cells leads to a loss of monooxygenase enzymes within $24 \mathrm{~h}$. As yet activity can only be retained with difficulty and at considerable cost (Michalopoulos et al. 1976).

In testing of chemicals for carcinogenicity there are two questions that need to be answered. (1) Does the chemical have the potential to be a carcinogen? and (2) is man susceptible to the chemical? These two questions can only be answered in 
different ways. To answer the first, one must use an activating system in which there are no detoxification enzymes and where there are as few competing nucleophiles as possible. In this way there is a greater chance of reactive metabolites reaching the target cell DNA. On the other hand, if one is anxious to determine species susceptibility or resistance, then it is essential to try and mimic in vivo conditions in vitro. This at the present time is almost impossible. A start in this direction is to examine whole cell systems such as hepatocytes which have a full complement of mono-oxygenases and conjugating enzymes. It should be remembered, however, that an animal or a human being is far more than a collection of liver cells. In addition, many carcinogens are not active in the liver but in other organs such as the intestine or the kidneys. In some cases these organs have the necessary activating enzymes but in others the liver carries out one of the metabolic steps and the target organ another. It would be necessary therefore to have a mixed culture system with the cell types of the two organs concerned. It may in the end be easier to use whole animals than mixed cell cultures containing all the cell types of interest.

I have concerned myself so far with mammalian cell enzymes for metabolic activation but many reactions in the body are catalysed by the gut flora. A limited amount of work has been carried out on the use of gut micro-organisms to activate carcinogens. One should be aware of the existence of bacterial enzymes which partake in carcinogen activation processes and that these may be important in the development of cancer (McCoy et al. 1979).

For mono-oxygenase function it is necessary to supplement the assay with reduced NADP. This is produced by endogenous liver glucose-6-phosphate dehydrogenase, glucose-6-phosphate and NADP. The amount of the latter cofactor is critical, in that the more one adds, the greater the amount of oxidation of the foreign compound one observes. It is not usual at present to supplement assays with other cofactors used in the metabolism of foreign compounds, but if we are to try and mimic in vivo conditions of metabolism this will have to be done. Information has appeared in the scientific literature on supplementation with UDPGA or PAPS but this is not something which is routinely carried out.

It should be emphasized that although to increase the sensitivity of in vitro assays induced mono-oxygenase enzymes are used, these same agents when coadministered with carcinogens to animals tend to reduce carcinogenicity. This is in contrast to in vitro studies, where increased amounts of activated metabolites are formed (for discussion, see Garner, r980).

\section{Detector organisms}

The composition of DNA from the simplest organism through to man appears to be identical. For this reason, agents which react with bacterial DNA will also react with mammalian cell DNA. In bacteria this reaction leads to both repair of DNA damage and, if this is not entirely faithful, to mutation. In mammalian cells repair is again seen after DNA reaction as well as mutation and possibly transformation. 
Micro-organisms. The use of micro-organisms for mutation research dates back some forty years or more. Their use for carcinogen screening, however, goes back only fifteen years. This difference in time relates to our lack of understanding that carcinogenic chemicals often require metabolism to exert their effects. Once this point was appreciated it was not long before it was suggested that bacterial mutation could be used to screen for carcinogens. There are now reports in the literature of tests of several thousand chemicals and the number tested increases almost daily. Here one can see mutagenicity tests' great advantage- that of speed. To carry out one test takes a little over $48 \mathrm{~h}$. There are a multitude of ways of carrying out a mutagenicity assay and there are many different indicator organisms that can be used. To score for mutation one takes an auxotrophic strain of bacteria (usually this takes the form of an amino acid requirement) and looks for conversion to prototrophy. The most widely used strains are those developed by Ames and his colleagues (Salmonella typhimurium) (Ames, 1979), but there is no reason at all why Escherichia coli cannot be used (Venitt, 1980). Increased sensitivity is achieved by using strains deficient in DNA repair. Failure to remove DNA damage increases the chances of mutation being induced. It is thought that many mutations occur not through mis-coding caused by the carcinogen reacting with DNA, but through misrepair. This occurs when lesions in the DNA are close together but in opposite strands; misrepair can be enhanced if the bacterial strains contain a plasmid such as $\mathrm{pKm}$ ror. The addition of this plasmid to either Salmonella or $E$. coli has greatly increased the sensitivity of mutagenicity assays. In the case of the Salmonella strains, permeability to organic molecules is enhanced by the use of deep rough strains. $E$. coli appear to be relatively permeable without alteration of the lipo-polysaccharide cell wall.

As the most widely used assays are those measuring reverse mutation arising through suppressor mutations it is necessary to screen chemicals with both frameshift and base-substitution tester strains. Mutation in the latter strains is thought to be through either a mis-coding or misrepair mechanism. In contrast, frame-shift mutations are caused by addition or deletion of base pairs in the DNA causing a slippage in the DNA reading frame. Carcinogenic chemicals can induce either frame-shift or base-substitution mutations or both. For this reason it is necessary to use different tester strains for screening purposes. There are a number of Salmonella strains available, all isolated by Ames, whereas for $E$. coli only basesubstitution mutants are readily available. The lack of frame-shift mutants available for testing in $E$. coli does not appear to be a problem. In the recent International Program for the Evaluation of Short-term Tests, the use of $E$. coli in place of Salmonella did not have any great effect on the sensitivity or specificity of the assay.

It would be easier if in a routine screen only a single strain of bacteria were required. With reverse-mutation systems this is not possible for reasons I have just described. If, however, a forward mutation system is used then base-substitution, frame-shift and deletion mutations could be tested. Several strains and assay 
systems are available but these are not at the present time widely used (Skopek et al. 1978; Pueyo \& Lopez-Barea, 1979).

Routine screening of chemicals is most often carried out using a soft-agar overlay technique. In this, bacteria, test compound and rat liver preparation are mixed together with soft-agar, overlaid onto minimal media plates and incubated for $4^{8 \mathrm{~h}}$ (Ames et al. 1975). Numbers of mutant bacteria are then counted. This type of assay suffers from the disadvantage of being only semi-quantitative. Results are expressed as mutants/plates at given concentrations of test chemical. One assumes that there is no difference in the numbers of surviving bacteria in plates with different concentrations of test chemical, something which can be tested if necessary. An alternative to the soft-agar overlay technique is the treat and plate method. Here the assay is carried out in liquid suspension and after the necessary incubation time the assay is quenched, aliquots taken for mutant determination, and serial dilutions carried out to determine numbers of surviving bacteria (Garner \& Wright, I973). Results are expressed as the numbers of mutant bacteria/survivors $\times 10^{6}$. This approach appears on theoretical grounds to be preferable. The inside of a liver cell is not normally heated up to $46^{\circ}$ or put into contact with soft-agar. However, reports in the literature using liquid suspension assays suggest that it is not as sensitive as the soft-agar method. A compromise assay between the soft-agar and the liquid suspension method with greater sensitivity than either is the fluctuation test. In this, bacteria, test chemical and liver are incubated together for some $18 \mathrm{~h}$ and minimal media then added. Only prototrophic bacteria can grow in the media so that after $2-3 \mathrm{~d}$ cultures containing revertant bacteria are turbid. The number of these are scored and compared statistically with controls. This assay appears to be some 1o-roo times as sensitive as a soft-agar overlay assay (Green et al. 1977). It is particularly useful for the screening of human body fluids for the presence of mutagens such as cigarette smoke metabolites, anti-cancer agents, etc.

Mammalian cells. There is a growing body of evidence to suggest that no one assay is adequate to test all compounds that need screening for potential carcinogenicity. This is because each assay throws up false-positive and falsenegative results. To circumvent this problem, particularly for false-negatives, it is necessary to put together a battery of tests to increase confidence that a real result has been obtained. Whereas there is little argument about the need to carry out a bacterial mutagenicity assay because of the good correlation between mutagens and carcinogens, there is much debate about the other sorts of test that can be used.

We have developed in our laboratories a DNA repair test using human cells in culture (Martin et al. 1978). The principle of the test is that carcinogen reaction with DNA leads to a repair response which can be monitored. We find that this test is extremely useful for screening purposes. In the recent International Program it came out well in terms of specificity and sensitivity, particularly when used in combination with bacterial mutagenicity assay results. Supplementation with liver $\mathrm{S}_{9}$ is necessary because of the low level of mono-oxygenase enzymes in HeLa cells. 
Certain carcinogenic compounds which are not readily detectable in a bacterial mutagenicity assay are readily detected using HeLa cells (Table 2). Reasons for this are not known but may be related to the two-step activation processes described earlier on. Other methods of measuring DNA repair and other cell types can also be used.

As an alternative to measuring DNA repair after carcinogen reaction one can measure two different biological endpoints, mutation or transformation (Hollstein et al. 1979). A variety of mutation systems are being used for screening. Nearly all depend on selection of resistant cells to drugs such as 8-azaguanine or ouabain. Only base-substitution mutations can be detected using the latter drug. This assay has therefore considerable mutagen specificity. A variety of cell lines can be used to screen for mutation. Again it is necessary to supplement with an $S 9$ preparation because cultured cells have only low mono-oxygenase activity. Alternatively, the detector cell can be co-cultivated with primary hepatocytes, activated metabolites being formed in these and diffusing to the tester cell. Only limited numbers of chemicals have as yet been tested for mammalian cell mutagenicity. It is not therefore possible to state which cell system is the most suitable for screening purposes. Although there may be aesthetic reasons for using human cells in culture there may be no real practical reasons for this since, as far as I am aware, no compound has been shown to be mutagenic to human cells which is not mutagenic to rodent cells.

Finally, a mammalian cell system which may reproduce the carcinogenic process in vitro is that of transformation. In this, one is measuring the conversion of a normal cell to a malignant one in tissue culture. There are several criteria for transformation which are used, including morphology, growth in soft-agar, or the production of tumours on injection into host animals. Cell transformation is a difficult assay to carry out, requiring considerable expertise and favourable culture conditions. Several cell lines are available including hamster embryo, mouse prostate and $\mathrm{BHK}$ cells. Some of these assays again require S9 supplementation while others do not. Just what the molecular mechanisms of transformation are is unknown. One of the unfortunate problems with transformation assays is their inability to 'travel' easily from one laboratory to another.

Table 2. False-negative mutagens: activity in a DNA repair assay

\begin{tabular}{|c|c|c|c|c|}
\hline Compound & Liver & $\begin{array}{l}\text { Active dose } \\
\text { range (M) }\end{array}$ & $\begin{array}{c}\text { Background } \\
\text { disintegrations/min } \\
\text { per } \mu \mathrm{g} \mathrm{DNA}\end{array}$ & $\begin{array}{c}\text { Maximum } \\
\text { disintegrations/min } \\
\text { per } \mu \text { g above } \\
\text { background }\end{array}$ \\
\hline Urethane & $\mathbf{p}$ & $10^{-3}-10^{-3}$ & $228+17$ & 111 \\
\hline Diethylstilboestrol & p & $10^{-6}$ & $275 \pm 25$ & 140 \\
\hline Dimethylaminoazobenzene & $\mathrm{P}$ & $10^{-3}-10^{-8}$ & $127 \pm 8$ & 44 \\
\hline
\end{tabular}




\section{Conclusions}

There are now a multitude of in vitro assays available. The ones described in this paper are the ones which appear to me to have the widest application for the screening of chemicals for potential carcinogenicity. The list of tests here is in no way exhaustive but includes those tests where the largest number of chemicals have been tested for validation purposes. A number of chemicals such as hormones and plastic films are known to be carcinogenic through unknown mechanisms. The tests described here are not suitable for these. Indeed, the central dogma underlying all the described tests is the somatic mutation theory of carcinogenesis. If this were incorrect then other tests than those described would have to be sought. It is hard, however, to understand the correlation between mutagens and carcinogens if this theory were not correct.

The idea of short-term tests for carcinogens is still only some 8-10 years old. There has been an explosive growth of interest in this area. We now require a period of time to consolidate our knowledge and more critically evaluate what is going on. For example, on the surface of an agar plate it is possible to have a very complex series of reactions. If this is not appreciated then some exceedingly stupid mistakes will occur, particularly at a legislative level. Do we wish to ban vitamin C because it is a mutagen? Without it we would be in a pretty sorry state!

\section{REFERENCES}

Ames, B. N. (1979). Science, N.Y. 204, $5^{87}$.

Ames, B. N., McCann, J. \& Yamasaki, E. (1975). Mutation Res. 31, 347.

Booth, S. C., Welch, A. M. \& Garner, R. C. (1980). Carcinogenesis (In the Press).

Doll, R. (1977). Nature, Lond. 265, $5^{89}$.

Garner, R. C. (1980). In Short-term tests for detecting carcinogens, p. 5 [K. H. Norpoth and R. C. Gamer, editors]. Berlin: Springer-Verlag.

Garner, R. C. \& Wright, C. M. (1973). Br. J. Cancer 28, 544.

Green, M. H. L., Bridges, B. A., Rogers, A. M., Horspool, G., Muriel, W. J., Bridges, J. W. \& Fry, J. K. (1977). Mutation Res. 48, 287.

Hollstein, M., McCann, J., Angelosanto, F. A. \& Nichols, W. (1979). Mutation Res. 65, I33. McCoy, E. C., Petrullo, L. A. \& Rosenkranz, H. S. (1979). Biochem. biophys. Res. Comm. 89, 859. Martin, C. N., McDermid, A. C. \& Garner, R. C. (1978). Cancer Res. 38, 2621.

Michalopoulos, G., Sattler, G., Sattles, C. \& Pitot, H. C. (1976). Am. J. Pathol. 85, 755.

Miller, J. A. (1970). Cancer Res. 30, 559.

Pueyo, C. \& Lopez-Barea, J. (1979). Mutation Res. 64, 249.

Robbins, J. H. (1978). J. natn. Cancer Inst. 61, 645.

Skopek, T. R., Liber, H. L., Krolewski, J. J. \& Thilly, W. G. (1978). Proc. natn. Acad. Sci. U.S.A. $75,410$.

Thomas, P. E., Lu, A. Y. H., Ryan, D., West, S. B., Kawalek, J. \& Lewin, W. (1976). f. biol. Chem. $25 \mathrm{x}, 1385$.

Venitt. S. (1980). Br. Med. Bull. 36, 57.

Wiebel, F. J. (s980). In Carcinogenesis-a comprehensive survey, vol. 5, p. 57 [T. J. Slaga, editor]. New York: Raven Press.

Williams, G. M. (1977). Cancer Res. 37, 1845.

Wynder, E. (1977). f. nain. Cancer Inst. 58,825. 